\title{
Efek Penambahan Fly Ash Tipe C Terhadap Kuat Tekan Mortar
}

\author{
Armin Naibaho ${ }^{1}$ dan Aulia Rahman ${ }^{2} *$ \\ 1,2 Jurusan Teknik Sipil Politeknik Negeri Malang \\ *e-mail corresponding author : mbah.persik@gmail.com
}

\begin{abstract}
ABSTRAK
Bahan alternatif pengganti semen mulai banyak dicari karena isu lingkungan. Proses pembuatan semen terindikasi sebagai salah satu penyumbang tertinggi dalam kadar $\mathrm{CO}_{2}$ di udara. Salah satu substansi yang banyak digunakan untuk bahan pengganti semen adalah fly ash karena sifatnya serupa dengan semen dan jumlahnya melimpah sebagai hasil residu pembakaran tungku batu hara di PLTU. Umumnya, fly ash dikelompokkan menjadi dua jenis yaitu tipe $\mathrm{C}$ dan $\mathrm{F}$. Tipe $\mathrm{C}$ jarang digunakan karena mudah mengeras. Namun, pada penelitian lebih lanjut, tipe ini memiliki kelebihan dalam meningkatnya kuat tekan umur prematur. Penelitian ini dibuat untuk mendapatkan rasio fly ash tipe $C$ yang tepat dengan cementitious material pada mortar. Secara teknis, penelitian dikerjakan dengan membuat sampel mortar dengan perbandingan komposisi $1: 3$, sedangkan faktor air semen sebesar $50 \%$. Kemudian, komposisi cementitious divariasikan antara PC dan fly ash, mulai dari $0 \%, 25 \%$, $50 \%, 75 \%$, dan 100\%. Pengetesan dilakukan hanya pada minggu pertama dan kedua untuk mengamati perkembangan kekuatan awal. Namun, tidak semua kombinasi bisa diujikan karena kekuatannya terlalu rendah. Hanya kombinasi fly ash $25 \%$ saja yang memberikan kekuatan $20 \mathrm{MPa}$ pada umur 7 hari, mengungguli sampel kontrol berkekuatan 19,36 Mpa. Sedangkan kekuatan sampel fly ash cenderung lebih rendah jika dibandingkan sampel kontrol.
\end{abstract}

Kata kunci : fly ash tipe C; mortar; kuat tekan.

\begin{abstract}
Alternative cement replacement are widely observed due to environmental issues. The processes of cement production are indicated as one of the bighest contributors in $\mathrm{CO}_{2}$ levels in the air. One of the substances used as alternative cement is fly ash because it is similar in nature to cement and the amount is abundant because it is a residual result of coal burning process in power plants. Generally, fly ash is classified into two types namely type $C$ and F. Type $C$ is rarely used because it is easy to harden. However, in further research, this type $C$ has advantages in increasing the compressive strength of premature concrete. This research was made to obtain the optimum type $C$ fly ash ratio with cementitious material on the mortar. Technically, the research was carried out by making mortar samples with a composition ratio of 1:3, while the cement water factor was 50\%. Then, the composition of cementitious is varied between PC and fly ash, starting from $0 \%, 25 \%, 50 \%, 75 \%$, and 100\%. Testing is conducted only in the first and second week to observe the development of the initial forces. However, not all combinations can be tested because the strength is too low. Only the $25 \%$ fly ash combination gives $20 \mathrm{MPa}$ strength at 7 days, which outperforms a control sample of $19.36 \mathrm{MPa}$. Henceforth, the strength of fly ash samples tends to be lower when compared to control samples.
\end{abstract}

Keywords : fly ash type C; mortar; compressive strength.

Cara Mengutip : Naibaho, A., Rahman, A. (2020). Efek Penambahan Fly Ash Tipe C Terhadap Kuat Tekan

Mortar. Reka Buana : Jurnal Ilmiah Teknik Sipil dan Teknik Kimia, 5(1), 51-56.

http://dx.doi.org/10.33366/rekabuana.v5i1.1612

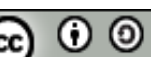

EY SA Content from this work may be used under the terms of the Creative Commons Attribution-ShareAlike 4.0 International License. Any further distribution of this work must maintain attribution to the author(s) and the title of the work, journal citation and DOI. 


\section{PENDAHULUAN}

Indonesia adalah salah satu negara penghasil batu bara terbesar di dunia. Begitu banyak PLTU yang dibangun mulai dari Jawa, Kalimantan, sampai Sulawesi, dan jumlahnya terus meningkat setiap tahun. Ini menunjukkan bahwa hasil samping dari pembakaran batu bara juga melimpah di Indonesia, dan fly ash adalah salah satu contohnya. Sebelumnya, fly ash hanya dianggap sebagai hasil residu pembakaran batu bara yang kurang dipandang nilainya.

Fly ash hanya akan berakhir sebagai material timbunan atau dibuang begitu saja, sehingga mengakibatkan dampak yang buruk bagi lingkungan sekitar. Faktanya, di banyak negara berkembang, fly ash sudah dilirik sebagai salah satu alternatif material pembuatan beton ramah lingkungan. Fly ash diteliti begitu luas untuk mengganti peran semen konvensional yang disinyalir sebagai salah satu penyumbang karbon dioksida $\left(\mathrm{CO}_{2}\right)$ terbesar selama proses manufaktur. Bahkan pada tahun 2013, disinyalir proses produksi semen telah menyumbang gas $\mathrm{CO}_{2}$ sebesar 2,8 juta ton per tahun atau sekitar $7 \%$ dari total polusi dunia. [7]

Pada penelitian sebelumnya, didapati bahwa fly ash tipe C memiliki dua sifat berbeda dengan tipe lainnya pada pembuatan sampel berupa pasta, yaitu waktu ikat awal yang lebih cepat, dan perkembangan kekuatan yang lebih baik di hari-hari awal pengujian [2][4]. Sifat inilah yang akan diteliti ulang dengan bentuk spesimen yang lebih kompleks, yaitu mortar. Pengujian akan dilakukan pada harihari awal proses hardening, yaitu 7 dan 14 hari saja. Kadar fly ash dalam cementitious material divariasikan mulai $0 \%, 25 \%, 50 \%$,
$75 \%$, bahkan $100 \%$. Sedangkan variabel yang dibuat sama adalah rasio cementitious material dan pasir, dan juga faktor air semen (FAS).

Adapun, tujuan penelitian ini adalah mendapati rasio fly ash manakah yang memberikan kuat tekan paling optimal di hari-hari awal hardening proses. Pada penelitian sebelumnya didatangkan beberapa jenis fly ash dari PLTU berbeda, dari Jawa dan Sulawesi. Berikut beberapa sampel tersebut beserta daerah asal dan kodenya: Paiton (FA1), Pacitan (FA2), Jeneponto (FA3), Tanjung Jati (FA4), Bayah (FA5), Petrokimia (FA6), Suralaya (FA7). [2]

Ketujuh sampel tersebut diuji melalui metode X-Ray Fluoresence (XRF) untuk diungkap kandungan oksidanya. Kemudian, tipe-tipe fly ash dari ketujuh sampel tersebut bisa dikelompokkan menggunakan ketentuan sebagai berikut : tipe $\mathrm{C}$ adalah fly ash dengan kadar $\mathrm{SiO}_{2}+\mathrm{Al}_{2} \mathrm{O}_{3}+\mathrm{Fe}_{2} \mathrm{O}_{3}>$ $50 \%$ dan kadar $\mathrm{CaO}$ mencapai 10\%, sedangkan fly ash tipe $\mathrm{F}$ adalah fly ash dengan kadar $\mathrm{SiO}_{2}+\mathrm{Al}_{2} \mathrm{O}_{3}+\mathrm{Fe}_{2} \mathrm{O}_{3}>70 \%$. Kadar $\mathrm{CaO}$ kurang dari 5\%. [1]

Dari ketujuh sampel tersebut didapat bahwa hanya sampel FA1 yang memenuhi syarat sebagai fly ash tipe C, sedangkan FA6 mendekati, dan sisanya adalah tipe $F$. Berikut hasil kuat tekan setelah pengujian selama 56 hari secara berkala tiap minggu. Didapat hasil bahwa kuat tekan sampel bertipe fly ash C, yaitu sampel yang bertanda silang (FA1) mengungguli sampel lainnya pada uji 3 hari pertama, namun pada akhir periode pengujian, kekuatannya lebih rendah daripada sampel bertipe $F$. 


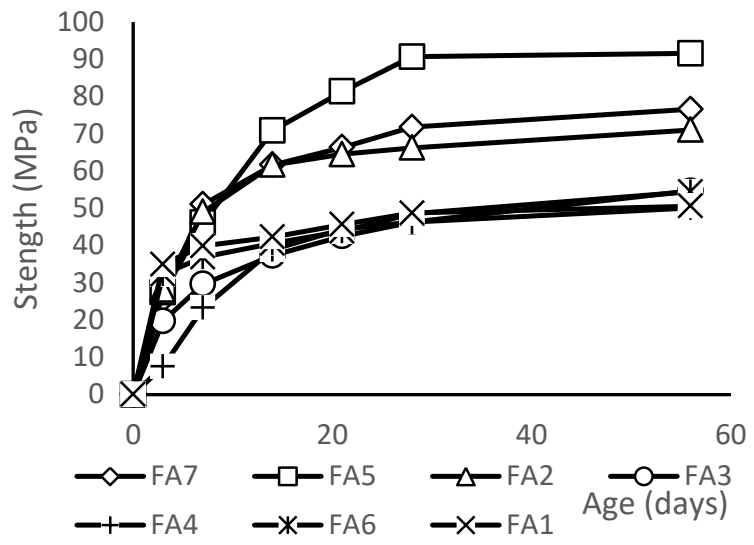

Gambar 1. Kuat Tekan Ketujuh Sampel Setelah Pengujian Selama 56 hari.[2]

Fenomena ini disinyalir akibat banyaknya senyawa kalsium (Ca) yang terkandung dalam fly ash tipe C. Kalsium merupakan unsur yang berperan sebagai sites, yang merupakan awal dari pembentukan rantai geopolimer. Semakin banyak sites yang terkandung, maka semakin pendek juga jarak antara inti geopolimerisasi. Sedangkan, proses geopolimerisasi dianggap berhenti jika rantai-rantai geopolimer bertemu dengan inti-inti lainnya. Berhentinya proses pembentukan rantai geopolimer berdampak pada material yang mulai mengeras. [6]

Tingginya kadar $\mathrm{CaO}$ dalam fly ash yang tinggi tidak baik untuk perkembangan kuat tekan di hari-hari akhir pengujian, bahkan disarankan kadar $\mathrm{CaO}$ yang baik pada fly ash adalah sebesar 5\% - 10\%. [2]

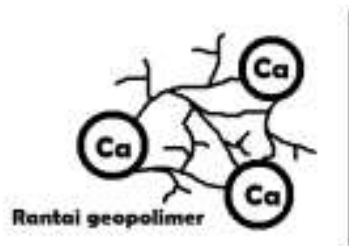

(a)

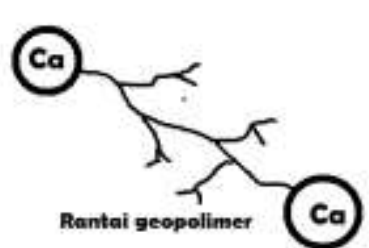

(b)
Gambar 2. (a) Ilustrasi geopolimerisasi yang terjadi pada pasta fly ash tipe C, (b) Ilustrasi geopolimerisasi yang terjadi pada pasta fly ash tipe F.

\section{METODE PENELITIAN}

Adapun material-material yang digunakan pada penelitian ini adalah :

- Fly ash tipe C

- Semen Portland

- Agregat halus

- Air

Sampel dibuat dengan variabel bebas berupa rasio fly ash dan semen, yaitu mulai $0 \%, 25 \%, 50 \%, 75 \%$, dan $100 \%$ atau $0 \%$ semen. Sedangkan variabel tetapnya adalah perbandingan cementitious material dan pasir sebesar 1 : 3, dan FAS sebesar 0,5. Mortar dicetak pada cetakan tembaga berbentuk kubus dengan dimensi $5 \times 5 \times 5 \mathrm{~cm}$.

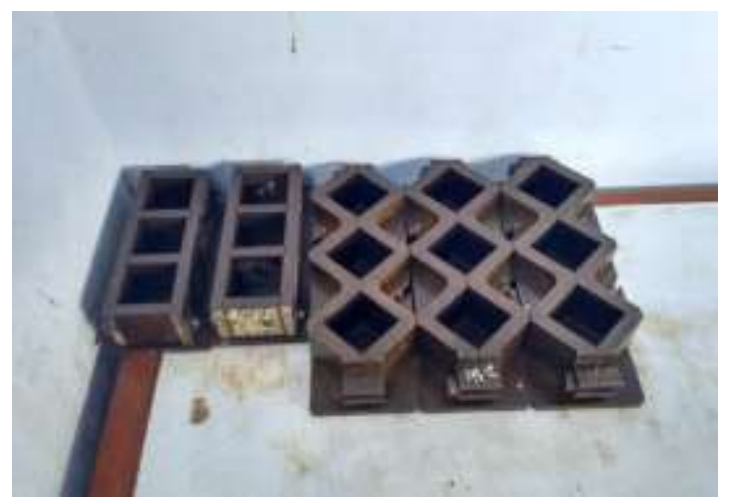

Gambar 3. Bentuk Cetakan Mortar.

Pengujian dilakukan pada umur 7 dan 14 hari dengan perulangan sebanyak 5 kali per item. Dan berikut adalah komposisi lengkapnya.

Tabel 1. Kebutuhan Komposisi Mortar.

\begin{tabular}{|c|c|c|c|c|c|c|}
\hline \multicolumn{3}{|c|}{ Komposisi } & \multicolumn{4}{|c|}{ Kebutuhan } \\
\hline \multicolumn{2}{|c|}{ Cementitious } & \multirow[b]{2}{*}{ Pasir } & \multirow{2}{*}{$\begin{array}{l}\text { Jumlah } \\
\text { sampel }\end{array}$} & \multicolumn{2}{|c|}{ Cementitious } & \multirow{2}{*}{$\begin{array}{c}\text { Pasir } \\
\text { (gr) }\end{array}$} \\
\hline Semen & FA & & & $\begin{array}{l}\text { Semen } \\
\text { (gr) }\end{array}$ & $\begin{array}{l}\text { FA } \\
\text { (gr) }\end{array}$ & \\
\hline 1 & 0 & 3 & 15 & 1.03 & 0.00 & 3.09 \\
\hline 0.75 & 0.25 & 3 & 15 & 0.77 & 0.26 & 3.09 \\
\hline 0.5 & 0.5 & 3 & 15 & 0.52 & 0.52 & 3.09 \\
\hline 0.25 & 0.75 & 3 & 15 & 0.26 & 0.77 & 3.09 \\
\hline 0 & 1 & 3 & 15 & 0.00 & 1.03 & 3.09 \\
\hline \multicolumn{3}{|c|}{ Total $(\mathrm{kg})$} & 75 & 2.58 & 2.58 & 15.47 \\
\hline
\end{tabular}

\section{Batasan Penelitian}

Adapun hal-hal yang dibatasi dalam penelitian ini adalah : 
- Penelitian dikerjakan dalam skala laboratorium.

- Semen yang digunakan tipe PC.

- Digunakan pasir Lumajang.

- Pengadukan campuran menggunakan mesin.

- Pengujian menggunakan mesin UTM.

- Dilakukan curing pada sampel berupa perendaman.

- Dilakukan analisis kimia untuk menentukan jenis fly ash saja.

\section{Hipotesis Penelitian}

- Berdasarkan uraian teori sebelumnya, diduga mortar berkomposisi fly ash tipe C akan menunjukkan nilai kuat tekan yang tinggi di hari-hari awal pengujian.

- Kuat tekan tidak menunjukkan perkembangan yang signifikan pada harihari pengujian selanjutnya.

\section{HASIL DAN PEMBAHASAN}

Setelah diujikan XRF pada sampel, didapatkan kandungan $\mathrm{CaO}$ sebesar 14,7\%, maka dipastikan bahwa fly ash tersebut adalah tipe $\mathrm{C}$, karena melebihi batas standar yaitu 10\%. Adapun beberapa kandungan yang dominan adalah silika oksida $\left(\mathrm{SiO}_{2}\right)$ sebesar 32,2\% dan besi oksida $\left(\mathrm{Fe}_{2} \mathrm{O}_{3}\right)$ sebesar 34,32\%. Sedangkan aluminium oksida $\left(\mathrm{Al}_{2} \mathrm{O}_{3}\right)$ menempati urutan keempat dengan $12 \%$.

Tabel 2. Hasil Uji XRF Sampel Fly ash.

\begin{tabular}{|c|c|c|c|c|c|}
\hline No & Kandungan & Kadar & No & Kandungan & Kadar \\
\hline 1 & $\mathrm{Al}_{2} \mathrm{O}_{3}$ & $12 \%$ & 9 & $\mathrm{Fe}_{2} \mathrm{O}_{3}$ & $34.32 \%$ \\
\hline 2 & $\mathrm{SiO}_{2}$ & $32.20 \%$ & 10 & $\mathrm{NiO}$ & $0.02 \%$ \\
\hline 3 & $\mathrm{~K}_{3} \mathrm{O}$ & $1.97 \%$ & 11 & $\mathrm{CuO}$ & $0.06 \%$ \\
\hline 4 & $\mathrm{CaO}$ & $14.70 \%$ & 12 & $\mathrm{MoO}_{3}$ & $1.80 \%$ \\
\hline 5 & $\mathrm{TiO}_{2}$ & $1.47 \%$ & 13 & $\mathrm{BaO}$ & $0.38 \%$ \\
\hline 6 & $\mathrm{~V}_{2} \mathrm{O}_{5}$ & $0.06 \%$ & 14 & $\mathrm{Eu}_{2} \mathrm{O}_{3}$ & $0.35 \%$ \\
\hline 7 & $\mathrm{Cr}_{2} \mathrm{O}_{3}$ & $0.09 \%$ & 15 & $\mathrm{Yb}_{2} \mathrm{O}_{3}$ & $0.02 \%$ \\
\hline 8 & $\mathrm{MnO}$ & $0.36 \%$ & 16 & $\mathrm{Re}_{2} \mathrm{O}_{7}$ & $0.24 \%$ \\
\hline
\end{tabular}

Namun, setelah proses pembuatan dan curing, ada beberapa sampel mortar yang tidak layak diujikan karena kekuatannya terlalu rendah, bahkan hancur setelah proses pelepasan dari cetakan. Hal ini terjadi pada sampel mortar dengan kandungan fly ash di atas 50\%. Maka pengujian untuk komposisi $75 \%$ dan $100 \%$ urung dilakukan. Ini disinyalir karena kadar semen yang terlalu rendah, sehingga tidak terjadi reaksi pengikatan dengan agregat halus.

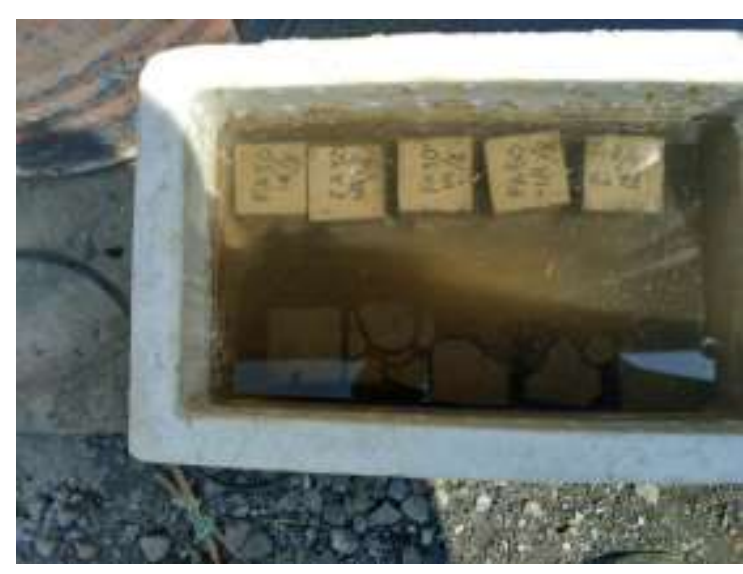

Gambar 4. Mortar hancur pada saat curing.

Pengujian dilakukan menggunakan alat Universal Testing Machine dengan kecepatan pembebanan sebesar $2 \mathrm{~kg} / \mathrm{cm}^{2} /$ detik. Data kuat tekan merupakan rata-rata dari 5 kali perulangan per kondisi. Dari grafik uji tekan terlihat bahwa sampel dengan kandungan fly ash 25\% mengungguli sampel kontrol yang terbuat dari 100\% Semen Portland. Nilai kuat tekan rata-rata pada umur 7 hari untuk sampel $25 \%$ fly ash adalah $20 \mathrm{MPa}$, sedangkan sampel kontrol hanya sekitar 19,36 MPa. Namun, seminggu berikutnya kekuatan sampel kontrol lebih unggul dengan 27,68 MPa, sedangkan sampel $25 \%$ fly ash hanya 24,96 MPa. Perbedaannya pun tidak begitu signifikan. Sedangkan untuk sampel $50 \%$ fly ash selalu menunjukkan kekuatan terendah yaitu $10,96 \%$ untuk 
pengujian 7 hari, dan $21,84 \%$ untuk pengujian 14 hari.

Pada penelitian lainnya yang telah dilakukan oleh Wenno , 2014, tren penurunan kuat tekan pada penambahan rasio fly ash ini juga terjadi. Hanya saja, pada penelitian tersebut, rasio fly ash dan cementitious material divariasikan lebih banyak, yaitu mulai $0 \%, 5 \%, 10 \%, 15 \%$, $20 \%$, sampai dengan 25\%. Dari semua waktu pengujian, baik itu 7, 14, ataupun 28 hari, semuanya menunjukkan tren penurunan kuat tekan, bahkan kekuatan terendah didapan pada komposisi 25\%. [8]

Adapun, hal lain yang disinyalir mempengaruhi perbedaan kuat tekan ini adalah rasio antara unsur silika dan aluminium. Jika unsur silika semakin besar, maka jumlah ikatan $\mathrm{Si}-\mathrm{O}-\mathrm{Si}$ juga semakin banyak. Di sisi lain, besarnya unsur aluminium, akan berakibat pada banyaknya ikatan $\mathrm{Si}-\mathrm{O}-\mathrm{Al}$. Secara teori, ikatan Si $\mathrm{O}-\mathrm{Si}$ lebih kuat daripada $\mathrm{Si}-\mathrm{O}-\mathrm{Al}$, maka semakin tinggi rasio $\mathrm{Si} / \mathrm{Al}$, semakin baik pula kuat tekannya. [5]

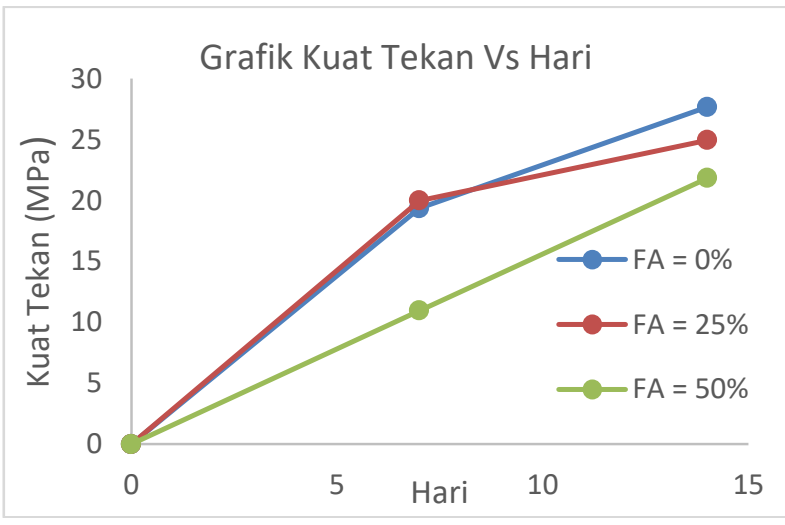

\section{Gambar 5. Grafik Uji Kuat Tekan Mortar pada Umur 7 dan 14 Hari.}

\section{KESIMPULAN}

Jika ditinjau dari segi kuat tekan, penambahan fly ash hampir atau tidak mempengaruhi perkembangan kuat tekan, jika dibandingkan variabel kontrol. Itulah sebabnya penambahan fly ash selama ini hanya dimaksudkan untuk pengurangan pemakaian semen. Bahkan, penambahan fly ash dalam porsi besar justru akan memperlemah kuat tekan mortar itu sendiri. Ini tampak pada gagalnya pengujian sampel dengan rasio di atas 50\%. Bahkan, efeknya sudah terlihat jelas saat pengujian rasio $25 \%$.

Berdasarkan hasil pengujian, nilai komposisi optimum adalah 25\%, karena tidak jauh berbeda dengan sampel kontrol $(0 \%$ fly ash $)$ dalam aspek kekuatan tekan. Namun, sesuai dengan karakteristik fly ash tipe C, nilai kuat tekan sampel 25\% juga menunjukkan peningkatan yang tidak besar seiring bertambahnya umur spesimen. Di samping itu, sampel dengan perbandingan komposisi $50 \%$ ke atas menunjukkan performa kuat tekan yang jauh lebih rendah daripada sampel kontrol, bahkan komposisi $75 \%$ dan 100\% tidak layak diujikan karena hancur selama proses curing.

Adapun saran terkait penelitian ini adalah pengujian kuat tekan sebaiknya dilanjutkan sampai hari-hari akhir hardening proses, yaitu minggu ke 3 sampai 4. Ini dilakukan untuk mengetahui performa sampel lebih lengkap, sehingga bisa diketahui apakah mortar fly ash memiliki sifat seperti penelitian sebelumnya, yaitu pasta fly ash. Sedangkan untuk penelitian selanjutnya, sebaiknya divariasikan komposisi sampel antara $0-25 \%$ saja, guna mengetahui lebih detail berapakan komposisi optimumnya.

\section{DAFTAR PUSTAKA}

[1] ASTM C618 (2004), Standard Specification for Coal Fly ash and Raw or Calcined Natural Pozzolan for Use in Concrete, West Conshohocken, USA. 
[2] Aulia Rahman. (2017), Karakterisasi Sifat Kimia dan Fisika Fly ash Indonesia. RC-142501, Intitut Teknologi Sepuluh Nopember, Surabaya.

[3] Diaz, E.I., Allouche, E.N., Eklund, S. 2010. "Factors affecting the suitability of fly ash as source material for geopolymers," Fuel, vol. 89, p. 992-996, 2010.

[4] Leonard Wijaya, Adhitya., Ekaputri, Januarti Jaya., Triwulan. 2017. Factors influencing strength and setting time of fly ash based-geopolymer paste. MATEC Web of Conferences 138, 01010 (2017) EACEF 2017.

[5] Mustofa., Pintowantoro, Sungging. 2016. The Effect of Si/Al Ratio to Compressive Strength and Water Absorption of Ferronickel Slag-based Geopolymer. The 2nd International Seminar on Science and Technology August 2nd 2016, Postgraduate Program Institut Teknologi Sepuluh Nopember, Surabaya, Indonesia

[6] Pangdaeng S et al. 2015. Apatite forming on calcined kaolin-white Portland cement geopolymer. Mater Sci Eng, C 2015;51:1-6.

[7] Vora, P., dan Dave, U. (2013), "Parametric Studies on Compressive Strength of Geopolymer Concrete". Procedia Engineering51 (2013)210-219.

[8] Wenno et al. 2014. Kuat Tekan Mortar Dengan Menggunakan Abu Terbang ( Fly Ash) Asal PLTU Amurang Sebagai Substitusi Parsial Semen. Jurnal Sipil Statik Vol.2 No.5, Juli 2014 (252-259) ISSN: 2337-6732. 